\title{
The Influence of Small One-size Clothes on the Female - With Brandy Melville as an Example
}

\author{
Ruohan $\mathrm{Hao}^{1, *}$ \\ ${ }^{1}$ JiLin University of Finance and Economics, Changchun, Jilin, 130000, China; \\ ${ }^{*}$ Corresponding author. Email: Guanghua.ren@gecacademy.cn
}

\begin{abstract}
The Italian fashion brand - Brandy Melville catapults to fame in a sudden summer, while the trend of cute one-size clothes has brought on the newest fashion trend. Girls and women all over the world have been crazily obsessed with it. This study investigates the potential harm that one-size clothes brought to females and the whole society's ideology.
\end{abstract}

Keywords: one-size clothes; fashion; Brandy Melville; trend

\section{INTRODUCTION}

It has been many years since one size of clothes as Brandy Melville brought to the public, the clothes are sorted as small one-size ones and oversized. Research shows that great harms of small one-size clothes are gradually permeating to females' perspective of the body, their psychology, and even views of modern society.

Brandy Melville, one of the most popular one-size brands, is an Italian clothing and fashion accessories brand established in 1970, marketing their products to teenage girls and young women, who are supposed to have smaller chests and smaller waist. According to an article on Business Insider from 2014, the fashion brand was one of the most popular teen brands at the timewhen analysts estimated Brandy Melville's annual company sales to be 125 million USD with a growth rate of 20 to 25 percent per year. [1]. Today, Brandy Melville boasts nearly 4 million followers on its Instagram account, which can be credited to the brand's continued success. However, with the spread of the popularity of Brandy Melville, so does the harm that exists to females.

However, true sizing standards hadn't developed until the 1940s. Before then, sizes for young ladies and children were all based on age. Back in the past, one of the most famous underwear brands, Victoria's Secret, started to produce one-size underwear in the last century, but failed, led to huge heated disputes of body discrimination and diversity [2]. This spring of 2020, Brandy Melville has also raised a trend of small one-size clothes, which are cute and smart with California style. It's like overnight. One size has become an indispensable fashion item for all girls. Brandy Melville has already achieved great success and made one-size clothes one of the most popular trends among girls. H\&M and Forever 21 , other teen retailers that previously carried all sizes, also started to carry only one size in some of their clothing, following Brandy Melville and the trend of one size clothes, which may also harm the female.

\section{PHYSICAL HARM TO INDIVIDUALS}

From the aspect of physical harm, "One size fits all" is the slogan of Bandy Melville. On Brandy Melville website, most of its clothes don't come with a size selection option. Instead, you've greeted with a note that the item in question fits "size XS to $\mathrm{S}$ " shown on the website page. 


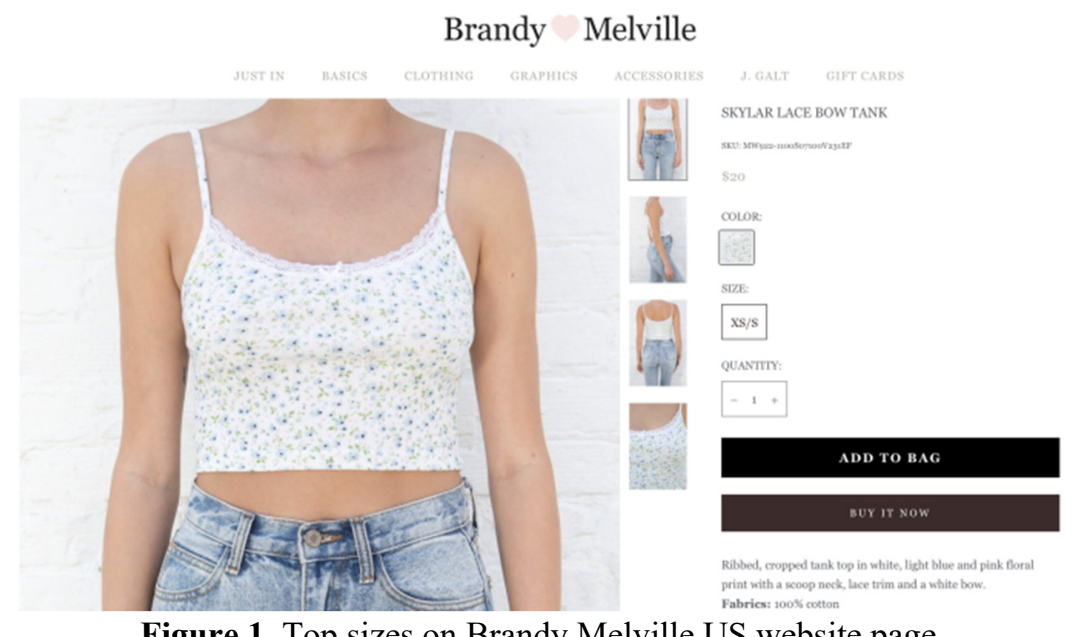

Figure 1. Top sizes on Brandy Melville US website page

A cursory click through several random items brings up largely the same results, with one or two items (all

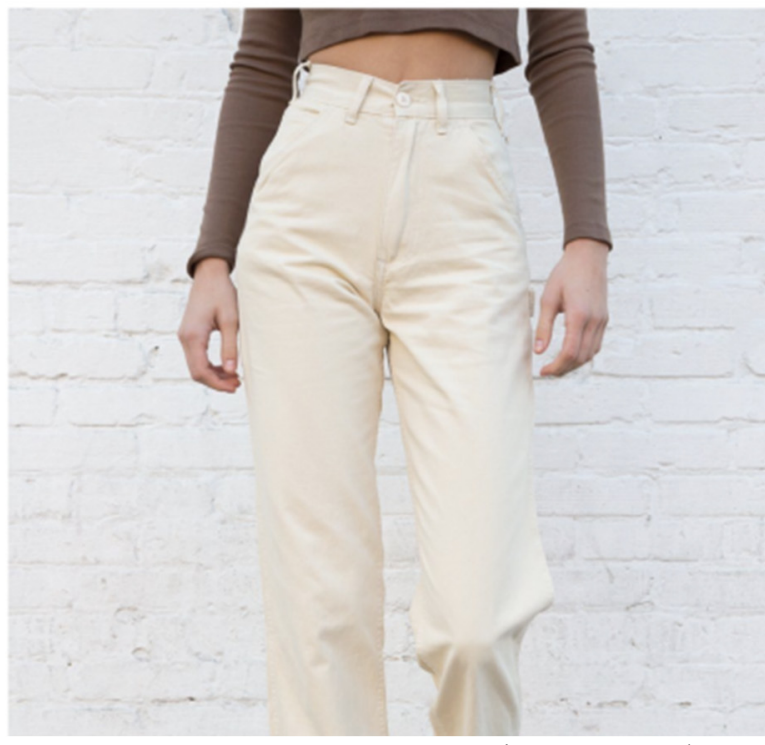

Figure 2. Pants sizes on Brandy Melville US website page pants or shorts) that come in two sizes, small or medium, such as the page shown below.
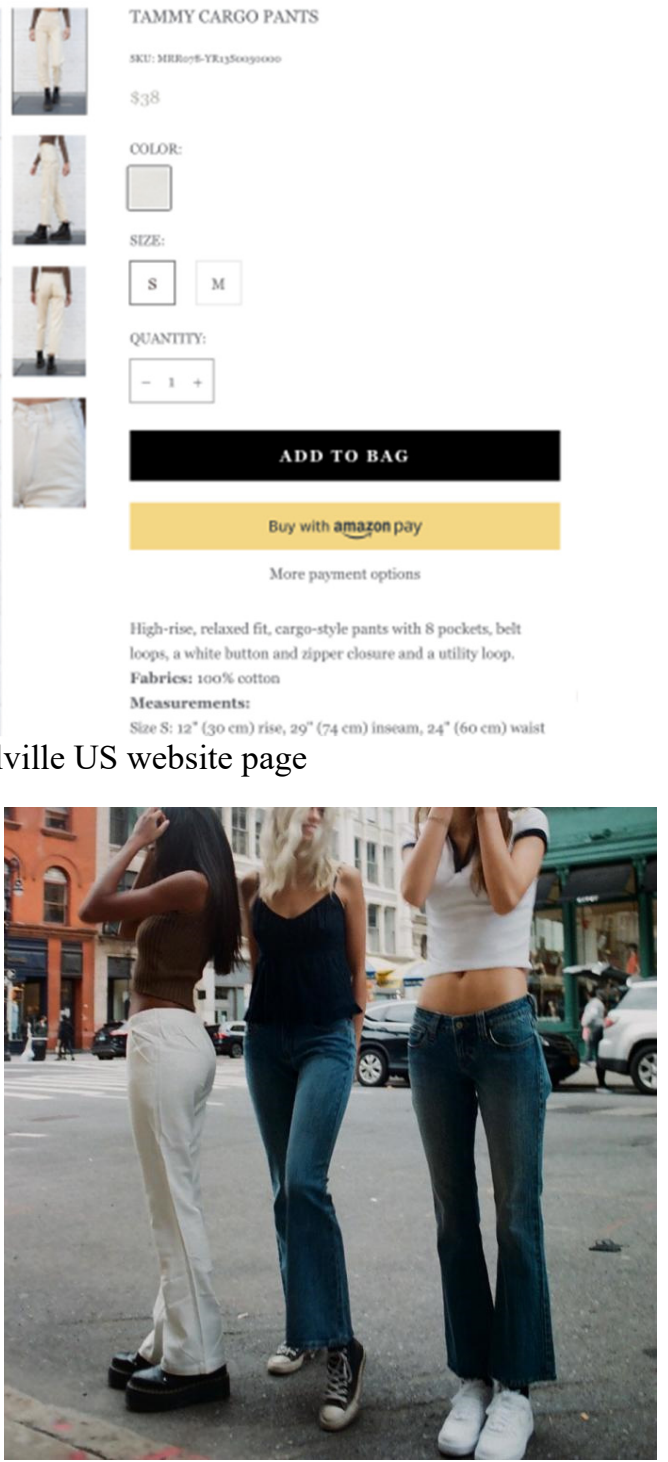

Figure 3. Models on Brandy Melville Instagram

However, according to a CDC report in 2012, the typical American 16-year-old is approximately 5'3', 
with a 31" waist. A CDC 2016 study suggested the average waist size for 13-19 years old girls is 32.6 inches[4]. The models on its Instagram seem to confirm it, with pictures of thin models across the board and no diverse body types of any kind. If one size clothes really fit any size body, why aren't all body types modeling for Brandy's website? This is a question worth thinking about for all one-size brand clothes. It's pretty clear that one size doesn't fit all, and it's also pretty clear which sizes are considered the universal "default" for this brand. When one-size clothing is regarded as an idealized figure, another controversy arises-when girls cannot fit in onesize clothing. They will think that they are abnormal, unfeminine, and unable. Adapting to the ideal body image established by society and thinking that they cannot catch the trend, they will feel anxious, doubt their body shape, and lose their self-confidence.

What's more, some girls adopt unreasonable and irregular ways to lose weight to wear one size clothes. (Sarah Gao, June 23, 2018) According to the National Eating Disorders Association, young people go to great lengths to meet these unreasonable societal expectations: More than 50 percent of teenage girls use unhealthy weight control behaviors such as skipping meals, fasting, smoking cigarettes, vomiting, and taking laxatives. (RINI SAMPATH, September 4, 2013) This can cause other hazards such as eating disorders. Approximately 7 million American girls and women have some form of a serious eating disorder, according to the South Carolina Department of Mental Health. For one-size clothing with young people as the main purchasing power, this will greatly affect the growth of young people. Brandy Melville's target customers are also the ages most exposed to this type of media. The company is feeding off the insecurities of young girls when they are probably the most insecure.

\section{PSYCHOLOGICAL HARM TO INDIVIDUALS}

From the aspect of psychological harm, girls who are larger or smaller than their idealized body may face a lot of challenges and insecurities. When more and more women are pursuing the so-called ideal body, they will not have the strength to resist when they are facing dangers.

Such clothes are also much likely to damage female's self-confidence and leave great damage and shame on them. With the fast and widespread internet, the idea of "perfect bodies fit in one size clothes" leaves deeply in the society. The girls who are not fitting in those would be regarded as "not perfect" or "flaw", even though they may have the healthiest body, but only not skinny enough to squiz in the one size clothes.

At the age of teenagers, people are dying to seek approval and attention from their friends and the opposite sex. When the clothing size, a standard that can be easily quantified, appears, teenagers will inevitably take it as the golden rule. Surveys show that $53 \%$ of 13 -year-old American girls are "unhappy with their bodies", and this number rises to $78 \% 17$-year-old girls. It is also found that among the U.S. adolescents aged 13 to 18 , eating disorders are more than twice as prevalent among females $(3.8 \%)$ than males (1.5\%) [5]. Raksha Sen, a junior at Saint Francis High School, "You feel uncomfortable returning the clothes. When the cashier asks you why you're returning them, you have to say that they're too small for your body." [6]

It is extremely hard not to obey once the rules of society establish, so as the rules of aesthetics. When the girls realize they are no longer fit in the normal rules of the society that everyone is following, it is causing much more way to feel pressure and stress, also psychological health. This type of store environment like Brandy Melville - one that emphasizes girls of other sizes are not welcome - is extremely damaging to female selfesteem.

The trend of one-size clothes started from Brandy Melville is followed by more and more fast fashion brands, such as Forever 21, H\&M, etc. Simultaneously, the harm to the individual and society is unpredictable. More and more girls are gradually weakening self-esteem instead of following the trend blindly without accurate analysis and critical thinking. The perfect becomes the loudest voice in public, no longer the most suitable for us. At that time, we would not be able to analyze but only follow the trend. We are no longer who we are. We are just one of the 60 billion population. While the variety of aesthetics would also disappear gradually, standardized beauty would be the basis of the world. Beauty becomes a theory that everyone should obey. The world will be lack color and variety.

\section{SOCIAL IDEOLOGICAL}

While one-size clothes leave great harm to the individual, at the same time, social ideology also has been influenced by it, which could be detrimental in the long term. In pop culture today, smaller sizes are linked to attractiveness, skinny, fashion, and perfection, whereas larger sizes are linked to fatness, poor self-control, rustic, and overweight. Brands of small one-size clothes set an "ideal" but unrealistic body for teens and watch teens striving for it. The culture behind sizes is actually thinspiration - no inclusivity, nobody diversity; the thinner, the better.

The phenomenon of body discrimination has also risen these years. For example, sizeism or size discrimination is the idea that their size prejudges people. As mentioned in the first point, Brandy Melville and other one-size clothes store only produces clothes in small sizes, so it is unfair for girls with unbalanced body 
proportions. Girls are much more likely to be shamed when they found the clothes don't fit on them, then strive to search for the issues on themselves, not the size itself. Gradually, the girls in other sizes would not be willing to step into the stores like this. The shops are not friendly enough for all types of bodies and people. More and more stores are following the trend of one sizing, people and the society are getting more and more strict on female's body. People would gradually leave unconscious impressions on the girls who do not fit in the one-size clothes, which is already happening in society right now. Larger sizes are linked to fatness, poor self-control, rustic, and overweight. The design concept of the clothing is that the skinny body is perfect. This is inconsistent with the standard of defining female figures in today's society, body diversity.

Diversity builds up society. Diversity in the fashion industry is important because with representation comes acceptance. Fashion has been a fundamental part of society since the invention of the catalog in 1872 . This industry has set the standard of beauty and makes society see certain groups in a certain way. With the growth of social media, increased discourse about the field of modeling has led to the realization that beauty is subjective. Participants in the fashion industry have been calling for a diversification of models on commercials, magazines, and runways worldwide.

Obviously, the demand for diversity in society has been a heated topic that many brands are appealing to gain public support. So, it would easily make sense for Brandy Melville to expand their range of models; as a popular brand among teenage girls, the extra diversity would attract customers looking for trendy clothing that suits them. However, the brand refuses. It also flourishes.

However, with the number of disputes on Brandy Melville or other brands of one-size clothes, most people still might own items themselves. Even I have quite a few Brandy Melville shirts, skirts, accessories. No one actually forces us to purchase, but the trend, the society, the crowds surround us have a powerful push on people's behaviors. Our desire to conform to today's trends triumphs our awareness of questionable actions done by brands; the inclusion we feel while wearing something popular comforts us by eliminating the possibility of being ostracized for being different. Whether it's due to low self-esteem, dependence on others, or fear, humans have always been drawn to conformity, and the fashion industry proves it. Throughout the decades, trends in clothing have symbolized the change in culture over time. In the 1920s, women were prancing around in short, shiny dresses, and in the 1950's they were sporting large skirts that were tight at the waist[7]. The trends of 2019 include jean shorts, mom jeans, and tight crop tops [8-10]. Brandy Melville provides all of these. Conforming to today's style allows people to feel involved in their culture and as a part of a community.

\section{CONCLUSION}

It is recognized that the brand like Brandy Melville of small one size clothes is making clothes for women. However, they are not pro-woman. It is beneficial for young girls to become conscious consumers who choose to support clothing brands that are inclusive of all types of people and recognize the value of promoting body positivity.

Size does not define you. In the past decade, the demand for the fashion industry to widen its range of shapes and colors has grown due to "body positivity" activism and a goal to eliminate the idea of whiteness as a global beauty standard. Fortunately, with the development of the "body positivity" movement, more and more brands offer special sections for plus-size clothing. For example, Forever 21 stores have a special section for "Plus+Curve" options with sizes ranging from " $0 \mathrm{X}$ " to " $3 \mathrm{X}$ ".

Aerie, a lingerie sub-company of American Eagle Outfitters, uses bodies of all sizes to display their underwear since 2014. Rejecting Photoshopping the models, Aerie uses the hashtag"\#AerieReal" on social media to show their models with visible spots, stomachs, stretch marks, and body rolls.

Everyone is different, and everyone is perfect. Size is just a number, and it never defines who you are.

\section{REFERENCES}

[1] Cuo dao, Kim, Though many people don't like this brand, it earned 2.1 billion RMB a year,2020

[2] Jie Ding, The Electronic Retailing: Though Victoria's Secret is bankrupt, this brand has gone viral,2020

[3] Prahl, A, Wondering Why Brandy Melville Only Carries One (Very Small) Size? We Are Too.

[4] India Sturgis, Test of " Can one size really fit all”, Daily Mail, March 21, 2018

[5] Information on http://www.bpr.berkeley.edu.com

[6] Chong, D., The Casual Clothing Line known for "One Size Fits All" clothes.

[7] Lucy Nemerov, 'One size fits all' fails to address body issues, December 6, 2017

[8] Sarah Gao, Brandy Melville's "one-size-fits-most" claim is a joke, June 23, 2018

[9] Rini Sampath, Brandy Melville fuels body dysmorphia, September 4, 2013

[10] Yu, V.,One Size Fits All? Clothing Sizes and Body Shaming. 